\title{
Chinese-Inspired Products: Value-Attitude-Behavior
}

\author{
Wei $\mathrm{Fu}^{1}$, Wanmo Koo ${ }^{1} \&$ Youn-Kyung Kim ${ }^{1}$ \\ ${ }^{1}$ Department of Retail, Hospitality and Tourism Management, University of Tennessee, Knoxville, Tennessee, \\ USA
}

Correspondence: Youn-Kyung Kim, Department of Retail, Hospitality and Tourism Management, University of Tennessee, USA. Tel: 1-865-974-1025. E-mail: ykim13@utk.edu

Received: March 26, 2014 Accepted: April 20, 2014 Online Published: May 21, 2014

doi:10.5539/ijms.v6n3p76 URL: http://dx.doi.org/10.5539/ijms.v6n3p76

\begin{abstract}
This study employed a value-attitude-behavior model to investigate whether global and domain-specific values affect US consumers' attitude and their behaviors toward a Chinese-Inspired Product, with the perceived level of cultural design influence as a moderator between cultural openness and esthetic value and emotional value. Data were collected by using the web survey from a major southeastern university. Total 323 surveys were retained.Theresults indicated that global values (i.e., cultural openness and need to differentiate) positively influenced domain-specific values (i.e., esthetic and emotional values) and attitude, which in turn affected US consumers' behaviors (i.e., word-of-mouth and purchase intention); and the effect of cultural opennesson emotional value perception was greater for consumers who had stronger perceptions of cultural design influence.
\end{abstract}

Keywords: Chinese-inspired product, cultural openness, need to differentiate, esthetic value, emotional value

\section{Introduction}

The US population more than tripled during the past century, with immigrants and their US-born descendants representing significant portion of the population gain (US Bureau of Census, 2013). Among all ethnic groups in the United States, Asian Americans have grown fastest in some areas of the United States, with Chinese Americans constituting most of this growth (US Bureau of Census, 2013). As a result, Chinese symbols and motifs such as dragon and lotus have caught Western consumers' attentions and have been part of the Western design source of inspiration (Delong, Wu, \& Bao, 2005). For example, Coach has embraced Chinese dragon as dragon-year wallet design; Nike Air Jordan has incorporated Chinese characters on their shoes design; and Ralph Lauren has used both Chinese dragon and characters on their T-shirt.

Acculturation, a process of adaptation to new conditions of life, has traditionally been viewed as a process through which ethnic consumers learn a mainstream culture (Laroche et al., 2007). However, the learning process may take place in either group or both groups. That is,it also can occur when mainstream consumers adopt styles of ethnicconsumers who reside in the same culture and bring their own cultures and traditions to a new country.

Culturally inspired products bring cultural elements into the design process and differentiate the designed object from others (Loughran, 2009). Similarly, a Chinese-inspired product (CIP) is the product whose design incorporates Chinese cultural symbols and styles into mainstream products. It is predicted that wearing Asian-inspired products will be one of the hottest consumer trends in the United States (Trendwatching, 2013). Given the fact that Chinese consumers account for the largest number of Asian consumers in the United States, this study uses a Chinese-inspired productas the research setting.

Research related to the flow of culture and its influences on consumer attitude and behaviors has been approached mainly from minority consumers' perspectives (Chattaraman \& Lennon, 2008; Xu et al., 2004). However, factors influencing consumer attitude and behaviors have not been examined from mainstream consumers' perspectives. To fill this gap, this study willexamine whether and which values of US consumers affect their attitude toward the CIP and eventually their behaviors. The findings will provide helpful tips to manufacturers and retailers in developing new products and repositioning their existing products.

\section{Theoretical Framework}

The conceptual framework, shown in Figure 1, integrates value system theoryand value-attitude-behavior model. 
Value system theory, introduced by Vinson, Scott, and Lamont (1977), indicates that values exist in a hierarchical structure, in which global values are at the fundamental level and domain-specific values are at the second level. Global values are abstract and general beliefs that guide actions and judgments across situations, while domain-specific values influence individuals' evaluative beliefs associated with the styles or attributes of products. The value-attitude-behavior framework proposes that value perceptions influence consumers' attitude, which eventually influence their behaviors (Homer \& Kahle, 1988).

This study tests these two models in the setting of a Chinese-inspired product (CIP). As illustrated in Figure 1, we propose that consumers' global values such as being culturally open and possessing the need to differentiate themselves influence their domain-specific values (i.e., esthetic value and emotional value) toward the CIP and that these domain-specific values positively influence their attitudetoward the productand ultimately their behaviorby way of word-of-mouth and purchase intention. In addition, this study will examine whether the perceived level of cultural design influence moderates the relationship between cultural openness and esthetic value and emotional value.

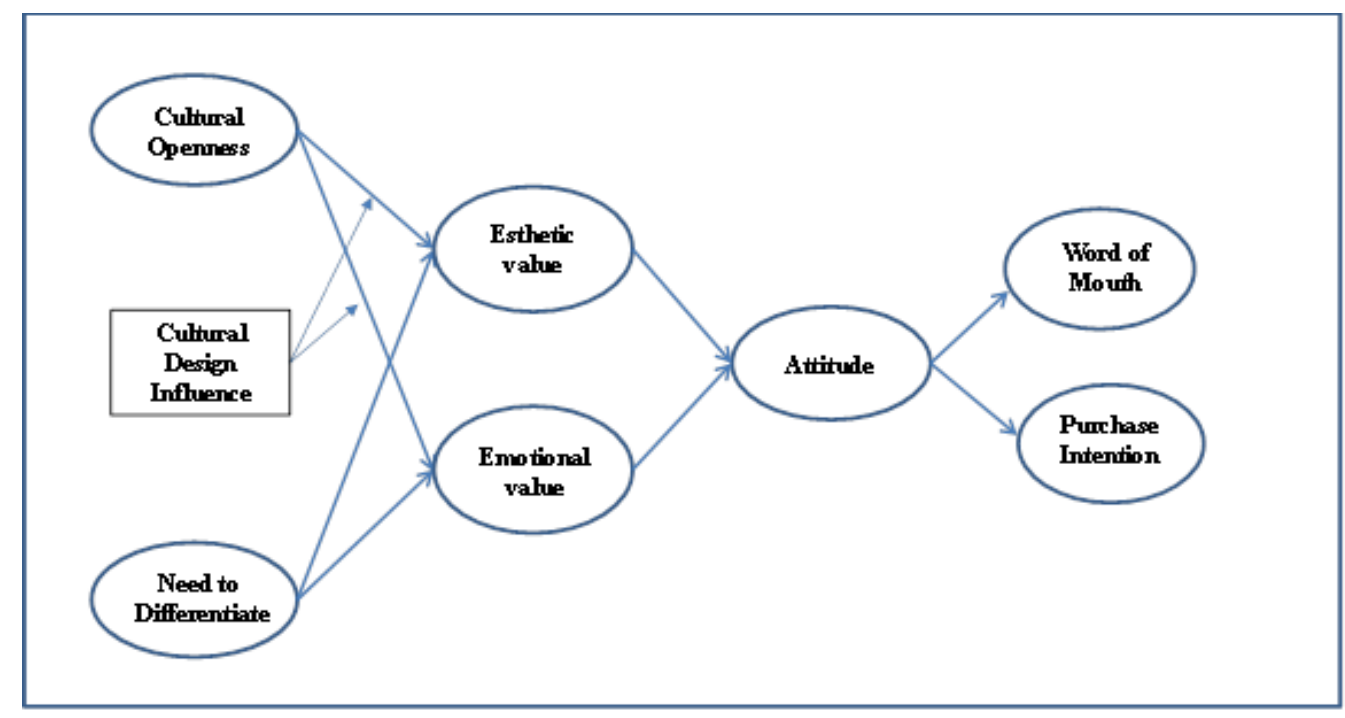

Figure 1. Conceptual model

\section{Literature Review and Hypotheses}

\subsection{Global Values}

This study employs cultural openness and need to differentiate as global values because they are closely related to the individual's self and provide guidelines for modes of conductand evaluations of products (Verplanken \& Holland, 2002).

\subsubsection{Cultural Openness}

Cultural openness refers to awareness, understanding and acceptance of other cultures and is determined by an individual's willingness to interact with people from other cultures and experience their artifacts (Shankarmahesh, 2006). In this culturally diverse world, individuals are directly and indirectly exposed to other cultures and thus are subjected to various levels of cultural influences, changing their views toward the cultures. According to Sharma, Shimp, and Shin (1995), the opportunity to interact with people and products from other cultures can lower cultural prejudice. For instance, with greater exposure to Chinese cultures, consumers become more familiar with and receptive to the Chinese cultures. Therefore, consumers who are culturally open like to meet people and learn from different cultures, and accept products that evoke cultural associations. Steenkamp, Batra, and Alden (2003) argued that cultural openness is an important variable that not only shapes consumers' responses to products but also determines preferences for foreign and local brands.

\subsubsection{Need to Differentiate}

Assimilation and differentiation are two competing needs, and each of them tends to happen at the expense of the other (Brewer, 1997). That is, as individuals become more inclusive by identifying themselves with the group as a whole, the need for assimilation is satisfied but the need for differentiation is activated. In the area of social 
psychology, need to differentiate refers to the extent to which an individual desires to be different from others (Brewer, 1997). Individuals who have a desire to define their self and develop a personal identity seek goods, services, and experiences to express their own thoughts and specialness (Kim \& Drolet, 2003). Thus, these consumers seek a higher level of dissimilarity from most other consumers, exhibiting a strong desire to possess unconventional products.

\subsection{Domain-Specific Values}

Domain-specific values bridge the gap between centrally held global values and evaluative beliefs about product attributes (Honkanen, Verplanken, \& Olsen, 2006). Among all attributes, style, fabric print, and color are viewed as important when US consumers evaluate ethnic-inspired garments, because these attributes convey cultural messages and trigger positive emotional reactions to the products (Moalosi, Popovic, \& Hickling-Hudson, 2007). Therefore, this study employs emotional value and esthetic value as domain-specific values relevant to a CIP rather than utilitarian values such as quality and price.

\subsubsection{Esthetic Value}

Esthetic value refers to individual perceptions of beauty (Armstrong, 2004). These perceptions involve responding to certain design elements such as symbol, style, and color (Veryzer, 1993) and interpreting their meanings (Scott, 1994). Therefore, the products that are predominantly esthetic tend to induce positive affective states (Mano \& Oliver, 1993) or intrinsic hedonic value that involves appreciating some experience for its own sake (Bell, Holbrook, \& Solomon, 1991).

Individuals with greater cultural experiences and contact with specific cultures tend more readily to accept people of the cultures and their dress (Chen \& Stanley, 1994). Caligiuri (2000) also argued that US consumers who are culturally open like to accept the products that incorporate different cultural elements. In this sense, culturally open consumers may perceive CIPs esthetically appealing because they contain unique design elements that project symbolic and cultural meanings. Thus,

\section{H1: US consumers' cultural openness is positively related to their perceived esthetic value toward a CIP.}

Individuals have a strong need to define their self with a meaningful identity, and products with certain designs can communicate this meaning (Belk, 1989). Specific attributes such as symbols and styles of a product can influence individuals to achieve desired values through the benefits derived from the product (Reynolds \& Gutman, 1988). This influence may be stronger among consumers who have the need for distinctiveness (Bloch, 1995). To these consumers, wearing ethnic clothing creates a unique and creative appearance (Littrell, Ogle, $\&$ Kim, 1999). Thus,

H2: US consumers' need to differentiate is positively related to their perceived esthetic value toward a CIP.

\subsubsection{Emotional Value}

Emotional value refers to individual perceptions of feeling or affective states (e.g., comfort, pleasure, happiness) generated by a product (Sweeney \& Soutar, 2001). According to Kim, Sullivan, and Forney (2007), consumers evaluate products, not just in functional terms of expected performance, value for money and versatility, but in terms of the enjoyment or pleasure derived from the product. Apparently, emotional value is a critical consumption-related value that is derived from the feeling or affective states that a product creates. Therefore, cultural symbols and styles of CIP scan induce some level of interest and contribute to pleasurable experiences from those who accept the cultural products. Thus,

H3: US consumers' cultural openness is positively related to their perceived emotional value toward a CIP.

Consumers who want to set themselves apart from others may view ethnic products as a vehicle to represent their self-identity because of their uniqueness and distinctiveness. In fact, Moalosi et al. (2007) discovered that products made in Botswana yielded both esthetically pleasing and sensually pleasurable experiences through their traditional motifs, colors, shapes and forms. Also, Radford and Bloch (2011) found that products perceived as visually new elicited more affective reactions than those not perceived as new. In this vein, it can be posited that US consumers who have a desire to differentiate themselves from others perceive the CIP as emotionally rewarding. Thus,

H4: US consumers' need to differentiate is positively related to their perceived emotional value toward a CIP.

\subsection{The Moderating Effect of Perceived Cultural Design Influence}

It has been acknowledged that design cues affect consumer perceptions toward stores or products. For example, Richardson, Dick, and Jain (1994) proved that consumers' store brand quality perception is driven by cues such 
as product display; and Aslam (2006) argued that color cues act as a perceptual tool for consumers' visual-affective functions. These findings lead us to speculate that the effect of cultural openness on esthetic and emotional values may not be same across consumers who perceive different levels of cultural design cues. For example, culturally open consumers may perceive CIPs more esthetically attractive and emotionally pleasing when they perceive CIPs have strong cultural design cues than when the perception of these cues is weak. To be brief, the effect of US consumers' cultural opennesson their perceived esthetic and emotional values can bemoderated by the perceived level of cultural design influence. Then, we predict that

H5: When culturally open US consumers perceive a higher level of cultural design influence from a CIP, they will perceive stronger esthetic value (H5a) and emotional value (H5b) from the CIP.

\subsection{Perceived Values, Attitude, and Behaviors}

Perceived values generate favorable evaluative beliefs that are attitude toward desirable attributes of products (Clawson \& Vinson, 1978). The relationship between perceived values and attitude has been demonstrated by several researchers (e.g., Honkanen et al., 2006; Sweeney \& Soutar, 2001). Osborne (1968) demonstrated that favorable attitudeis formed when an individual attends to products by its intrinsic attractiveness. Furthermore, Morganosky (1984) found that esthetic value, more than utilitarian value, is related to US consumers' favorable evaluations of apparel products. Likewise, these favorable evaluations can be influenced by consumers' pleasure or enjoyable feeling aroused by the CIP'scultural conspicuousness in design. Based on this review, we propose that

H6: Consumers' perceived esthetic value (H6a) and emotional value (H6b) are positively related to their attitude toward a CIP.

An individual's attitude isone of the important factors determining behavior (Ajzen \& Fishbein, 2000). Attitude-behavior relation has been proved by several researchers (e.g., Hansen, 2008; Michaelidou \& Hassan, 2007). Positive word-of-mouth (WOM) is a referral behavior that occurs when individuals speak products or services in a positive way (Money, Gilly, \& Graham, 1998). Thus, a favorable attitude toward products and service leads to positive word-of-mouth. Purchase intention is another construct that is guided by attitude and is used to anticipate a response behavior (Li, Daugherty, \& Biocca, 2002). Chitturi, Raghunathan and Mahanan (2008) found that delighted customers are more likely to express positive WOM and indicate the intention to purchase. Therefore, it is expected that US consumers having favorable attitude toward the CIP are more likely to purchase and express positive WOM about the CIP than their counterparts. We hypothesize that

H7: Consumers' attitudetoward a CIP is positively related to their WOM (H7a) and purchase intention (H7b) about the CIP.

\section{Methods}

\subsection{Stimuli and Data Collection}

A picture of black T-shirt containingthe peace sign embedded with Chinese characters was used as a stimulus. The design of the original peace sign was adapted by adding Chinese characters for the term "peace" and multiple colors inside the circle. We use the peace sign and Chinese characters because peace sign is internationally recognized and because Chinese symbols and characters have widely been embedded in products and service, thus increasing consumer awareness and familiarity. Face validation was performed by several graduate students from different ethnic groups (i.e., American, Chinese, and Korean) to check whether the stimulus represents a culturally inspired product. Then, the image of the stimulus was presented on the online survey developed via Qualtrics.

Data were collected via the snowballing sampling method with students taking one of the consumer behavior classes at a major southeastern university. Although this sampling method has limitation such as non-random data and sampling bias, it has been used to widen respondents' age range (Salganik \& Heckathorn, 2004). To maximize this benefit, the students were asked to invite people across the age spectrum to complete the survey. Among a total of 348 cases collected, 25 cases were excluded due to careless and incomplete responses. As a result, 323 surveys were retained.Among them, $72.3 \%$ were females, ages ranged from 18 to 77 with the mean age of 25 , and the majority $(90.9 \%)$ of respondents was white American.

\subsection{Measures}

All measures were adapted from previous studies and used 7-point Likert scale ranging from 1 (strongly disagree) to 7 (strongly agree). For global values, the cultural openness scale was adopted from Sharma, Shimp, and Shin (1995); and need to differentiate, from Zhang and Khare (2009). For two perceived product values, the esthetic 
value scale was adopted from Argo and Main (2008); and emotional value, from Sweeney and Soutar (2001). The scale items of attitude were derived from Batra and Ahtola (1990). For two scales of behavior, word-of-mouth was adapted from Arnett, German, and Hunt (2003); and purchase intention, from Rodgers (2004).All measurement items used in this study are presented in Table 1.

Table 1. Measures

\begin{tabular}{|c|c|c|c|c|}
\hline Construct & Items & S.L. ${ }^{\mathrm{a}}$ & $\mathrm{CR}^{\mathrm{b}}$ & $\mathrm{AVE}^{\mathrm{c}}$ \\
\hline \multirow{5}{*}{$\begin{array}{l}\text { Cultural } \\
\text { openness }\end{array}$} & I would like to have opportunities to meet people from China. & 0.810 & 0.940 & 0.760 \\
\hline & I would like to learn more about China. & 0.894 & & \\
\hline & I have a strong desire to travel to China. & 0.827 & & \\
\hline & I would like to know more about Chinese cultures and customs. & 0.929 & & \\
\hline & I have a strong desire to meet and interact with people from China. & 0.893 & & \\
\hline \multirow{3}{*}{$\begin{array}{l}\text { Need to } \\
\text { differentiate }\end{array}$} & I feel the need to be different from others in what I wear. & 0.900 & 0.941 & 0.843 \\
\hline & I feel I need to stand apart from others in what I wear. & 0.979 & & \\
\hline & I feel I am quite distinctive from others in what I wear. & 0.872 & & \\
\hline \multirow{3}{*}{ Esthetic value } & This T-shirt is appealing. & 0.916 & 0.956 & 0.878 \\
\hline & This T-shirt is nice-looking. & 0.955 & & \\
\hline & This T-shirt has good appearance. & 0.939 & & \\
\hline \multirow{3}{*}{ Emotional value } & This T-shirt is the one that I would enjoy. & 0.836 & 0.936 & 0.831 \\
\hline & This T-shirt would make me feel good. & 0.941 & & \\
\hline & This T-shirt would give me pleasure. & 0.953 & & \\
\hline \multirow{3}{*}{ Attitude } & This T-shirt is positive. & 0.646 & 0.864 & 0.685 \\
\hline & I like this T-shirt. & 0.934 & & \\
\hline & This T-shirt is favorable. & 0.875 & & \\
\hline \multirow{3}{*}{ Word-of-mouth } & I would "talk up" this T-shirt to people I know. & 0.883 & 0.952 & 0.868 \\
\hline & $\begin{array}{l}\text { I would bring up this T-shirt in a positive way in conversations I have with friends and } \\
\text { acquaintances. }\end{array}$ & 0.957 & & \\
\hline & In social situations, I would often speak favorably about this T-shirt. & 0.953 & & \\
\hline \multirow{2}{*}{$\begin{array}{l}\text { Purchase } \\
\text { intention }\end{array}$} & I would like to purchase this T-shirt. & 0.938 & 0.916 & 0.846 \\
\hline & I'm interested in buying this T-shirt. & 0.902 & & \\
\hline
\end{tabular}

Note. $\mathrm{SL}^{\mathrm{a}}=$ standardized loading; $\mathrm{CR}^{\mathrm{b}}=$ composite reliability score; $\mathrm{AVE}^{\mathrm{c}}=$ average variance extracted.

\subsection{Data Analyses}

The study tested a measurement model with confirmatory factor analysis (CFA) and tested hypotheses with structural equation modeling (SEM) using Mplus Version 6.1. Prior to testing models, we checked multivariate normality with LISREL 8.80 , and the result showed that data were not multivariate normal (chi-square of skewness and kurtosis values $=2134.43, \mathrm{p}<.000$ ). Therefore, we specified the robust maximum likelihood estimation method which uses a mean-adjusted chi-square test statistic (Satorra \& Bentler, 2010) on both CFA and SEM to control the non-normal data.

Model fits of CFA and SEM were assessed by the comparative fit index (CFI), the Tucker Lewis index (TLI), and the root mean square error of approximation (RMSEA). CFI and TLI above .90 and RMSEA under or equal to .08 are considered as acceptable goodness-of-fit indices (Hair et al., 1998).

\section{Results}

\subsection{Measurement Model}

CFA was tested for 7 variables with 22 scale items. The goodness-of-fit indices of the measurement were found to be satisfactory: $\mathrm{CFI}=.969$; $\mathrm{TLI}=.961 ; \mathrm{RMSEA}=.056$. All factor loadings exceeded the threshold of 0.50 (Rencher, 2002), and composite reliability scores also exceed the threshold of 0.70 (ranging 0.864-0.956) (Nunnally \& Bernstein, 1994). In addition, the average variance extracted (AVE) values of all construct exceeded the threshold of 0.50 (Fornell \& Larcker, 1981). These results of factor loadings, composite reliabilities, and AVE values demonstrate the existence of convergent validity (Table 1). Discriminant validity was also demonstrated by the finding that all AVE values exceeded shared variances of all possible pairs of latent variables (Fornell \& Larcker, 1981). 


\subsection{Structural Model}

We tested all hypotheses with SEM, and the structural model showed acceptable model fit indices: CFI $=.931$; TLI $=.920 ;$ RMSEA $=.081$. Cultural openness positively affected esthetic value $(\beta=.233, p<.001)$, supporting H1. However, need to differentiate did not significantly affect esthetic value $(\beta=.072, p=.184)$, not supporting H2. Emotional value is positively affected by both cultural openness $(\beta=.172, p<.001)$ and need to differentiate $(\beta=.145, \mathrm{p}<.05)$, supporting $\mathrm{H} 3$ and H4. In addition, both perceived esthetic value $(\beta=.584, \mathrm{p}$ $<.001)$ and emotional value $(\beta=.555, \mathrm{p}<.001)$ positively affected attitude, supporting H6a and H6b. Attitude positively affected both WOM $(\beta=.690, \mathrm{p}<.001)$ and purchase intention $(\beta=.816 \mathrm{p}<.001)$, supporting $\mathrm{H} 7 \mathrm{a}$ and $\mathrm{H} 7 \mathrm{~b}$.

\subsection{Multiple Sample Analysis}

We tested the moderating role of perceived cultural design influence in the effect of cultural openness on esthetic value (H5a) and emotional value ( $\mathrm{H} 5 \mathrm{~b}$ ) by conducting multiple sample analysis. We divided the sample into two groups based on respondents' perceived cultural design influence measured by three items: "This T-shirt is culturally inspired"; "This T-shirt is an ethnic-oriented product"; and "I see a cultural cue from this T-shirt." This scale of perceived cultural design influence was highly reliable with Cronbach's alpha value of .929. For a clear distinction between low and high group based on perceived cultural design influence, we excluded respondents who responded 4 (neutral response based on 1-7) on the constructs.

Before comparing causal paths across groups, we tested measurement model invariance between high and low groups. First, we tested configural invariance to check equality of the factor structure between the two groups, and the result showed excellent model fit indices: $\mathrm{CFI}=.947$; TLI $=.934$; RMSEA $=.075$, supporting configural invariance. We also tested metric invariance to check equality of factor loadings between the groups. After relaxing one factor loading (This T-shirt is the one that I would enjoy) based on modification indices, the partial invariance was supported $\left(\chi_{\mathrm{d}}^{2}(14)=19.214, \mathrm{p}=.157\right)$.

Next, we tested chi-square difference between the baseline model (all paths were made equal between groups) and the constrained model (a specific path was relaxed) in order to determine whether the particular path is significantly different. As for the path from cultural openness to esthetic value, there was no significant difference between the low group $(\beta=.077, \mathrm{p}=.369)$ and the high group $(\beta=.193, \mathrm{p}<.001)\left(\chi_{\mathrm{d}}^{2}(1)=2.185, \mathrm{p}\right.$ $=.139$ ). Therefore, $\mathrm{H} 5 \mathrm{a}$ was not supported. In terms of the path from cultural openness to emotional value, there was a significant difference between the low group $(\beta=-.115, \mathrm{p}=.167)$ and the high group $(\beta=.233, \mathrm{p}<.01)$ $\left(\chi_{\mathrm{d}}^{2}(1)=5.542, \mathrm{p}<.05\right)$, demonstrating the moderating effect of perceived cultural design influence for the relationship between cultural openness and emotional value. Thus, H5b was supported.

\section{Discussion and Implications}

This study used value system theory and value-attitude-behavior model to investigate the relationships among consumer values, attitude, and behavior toward a Chinese-inspired product (CIP). The result confirms the traditional value-attitude-behavior model but offersan extension to this model by adding hierarchically related global and domain-specific values. The findings also empirically support that acculturation occurs when ethnic consumers and their cultures influence mainstream ones, which is different from the traditional view of acculturation that occurs in a reversed way. This creates opportunities for manufacturers and retailers because the CIP can mold US consumers' attitude and behaviors.

The findings suggest that US consumers who are culturally open perceive esthetic appeals and emotional reward from the CIP because they believe that cultural symbols or styles of the CIP represent their openness and acceptance toward Chinese cultures. Therefore, retailers can identify US consumers who are culturally open as their target consumers of CIPs.

US consumers with a strong need to differentiate from others are willing to engage in the consumption of CIPs to express their own thoughts and develop a personal identity. To these consumers, the cultural symbols and styles of CIPs can be perceived as pleasing and visually attractive. In order to satisfy their desire to be different from others, designers can provide unique, stylish and symbolic features to generate consumers' positive value perception. For example, the qipao designed by Jason Wu incorporates Chinese attributes such as peony and deep red color that indicate the elegance and good luck to increase consumers' awareness. The red wedding dresses by Vera Wang use the Chinese traditional color to project the meaning of "happy ever after" to attract married couple's attention. These strong ethnic cues certainly increase the uniqueness of the products, serving the desire of those who want to differentiate themselves from others. 
Based on the significant result of the moderating effect of cultural design influence, we found that US consumer who are culturally open receive a strong emotional reward when they perceive a strong cultural design cue from the CIP; and US consumer who are culturally open do not receive emotional reward toward the CIP when they do not perceive cultural design cue. To arouse consumer perception toward cultural design influence, retailers can provide ethnically inspired store environment such as playing traditional Chinese music and adding Chinese decor in stores.

As expected, consumers have favorable attitude toward the CIP if they perceive the CIP as emotionally pleasing and esthetically attractive. Because values such as attractiveness, enjoyment, and pleasure are what these consumers perceive as important when choosing CIP products, retailers or manufacturers need to deliver such values to these consumers in their promotional or advertising strategies in order to succeed in the long run. Specifically, manufacturers can capitalize on this fact when they develop new products or extend their brands.

The finding that consumers' attitude is positively related to their word-of-mouth and purchase intention about the CIP indicates that consumers' favorable attitude toward the CIP supports their referral behavior and their response behavior of the CIP. To generate consumers' favorable attitude toward the CIP and increase their positive word-of-mouthand purchase intention, manufacturers and retailers can create their own Twitter accounts or post the CIP image on Facebook. In addition, retailers and manufacturers can provide live broadcasting fashion show on their blogs to publicizethe CIP's ethnic attributes and trigger consumers' positive behavioral responses. These strategies will certainly form consumers'positive attitude toward the CIP and support their referral behavior and their response behavior toward the CIP, which in turn extend product lifecycle, produce a high level of sales, and increase the competitive retail advantage.

However, this study has several limitations that lead to recommendations for future studies. First, this study was confined to a China-inspired product. Future studies may apply the value-attitude-behavior modelto other culturally inspired designs to determine the generalizability of the model in different cultural contexts. Second, the sample was regional in nature. Future studies can be conducted using nationwide sample that is more comprehensive in terms of both age and income groups. Finally, exploring the hierarchical relationships of all constructs in the on-line environment would be another future research area. Nevertheless, this study is the first to investigate the acculturation effect on mainstream consumers who have been influenced by ethnic designs and its explanatory variables based on the extended value-attitude-behavior model.

\section{References}

Ajzen, I., \& Fishbein, M. (2000). Attitudes and the attitude-behavior relation: reasoned and automatic processes. European Review of Social Psychology, 11, 1-33. http://dx.doi.org/10.1080/14792779943000116

Argo, J. J., \& Main, K. J. (2008). Stigma by association in coupon redemption: Looking cheap because others. Journal of Consumer Research, 35, 559-572. Retrieved from http://www.jstor.org/stable/10.1086/591102

Armstrong, J. (2004). The Secret Power of Beauty. Allen Lane, London.

Arnett, D. B., German, S. D., \& Hunt, S. D. (2003). The identity salience model of relationship marketing success: The case of nonprofit marketing. Journal of Marketing, 67, 89-105. http://dx.doi.org/10.1509/jmkg.67.2.89.18614

Aslam, M. M. (2006). Are you selling the right colour? A cross-cultural review of colour as a marketing cue. Journal of Marketing Communications, 12, 15-30. http://dx.doi.org/10.1080/13527260500247827

Batra, R., \& Ahtola, O. T. (1990). Measuring the hedonic and utilitarian sources of consumer attitudes. Marketing Letters, 2, 159-170. http://dx.doi.org/10.1007/BF00436035

Belk, R. W. (1989). Possessions and the extended self. Journal of Consumer Research, 15, 139-168. Retrieved from http://www.jstor.org/stable/2489522

Bell, S. S., Holbrook, M. B., \& Solomon, M. R. (1991). Combining esthetic and social value to explain preferences for product styles with the incorporation of personality and ensemble effects. Journal of Social Behavior and Personality, 6, 243-274.

Berry, J. W. (1997). Immigration, acculturation, and adaptation. Applied Psychology, 46, 5-34. http://dx.doi.org/10.1111/j.1464-0597.1997.tb01087.x

Bloch, P. H. (1995). Seeking the ideal form: product design and consumer response. Journal of Marketing, 59, 16-29. Retrieved from http://www.jstor.org/stable/1252116

Boone, D. (2013). Asian-inspired fashion finds to join this season's far-east movement. Style Blazer. Retrieved 
from

http://styleblazer.com/162212/trend-to-try-10-asian-inspired-fashion-finds-to-join-this-seasons-far-east-mov ement/

Brewer, M. B. (1997). The social psychology of intergroup relations: can research inform practice? Journal of Social Issues, 53, 197-211. http://dx.doi.org/10.1111/j.1540-4560.1997.tb02440.x

Caligiuri, P. M. (2000). Selecting expatriates for personality characteristics: a moderating effect of personality on the relationship between host national contact and cross-cultural adjustment. Management International Review, 40, 61-80. Retrieved from http://www.jstor.org/stable/40835867

Chattaraman, V., \& Lennon, S. J. (2008). Ethnic identity, consumption of cultural apparel, and self-perceptions of ethnic consumers. Journal of Fashion Marketing and Management, 12, 518-531. http://dx.doi.org/10.1108/13612020810906164

Chen, H., \& Stanley, L. A. (1994). Adaptation of Chinese design in Western contemporary dress. Perceptual and Motor Skills, 79, 731-737. http://dx.doi.org/10.2466/pms.1994.79.2.731

Chitturi, R., Raghunathan, R., \& Mahanan, V. (2008). Delight by design: The role of hedonic versus utilitarian benefits. Journal of Marketing, 72, 48-63. http://dx.doi.org/10.1509/jmkg.72.3.48

Chung, E., \& Fischer, E. (1999). It's who you know: intracultural differences in ethnic product consumption. Journal of Consumer Marketing, 16, 482-501. http://dx.doi.org/10.1108/07363769910289587

Clawson, C. J., \& Vinson, D. E. (1978).Human values: a historical and interdisciplinary analysis. Advances in Consumer Research, 5, 396-402.

Coelho, D. A., Silva, A. S., \& Simao, C. S. M. (2011). Culturally inspired design: product personalities to capture cultural aspects. http://dx.doi.org/10.5772/20327

Delong, M., Wu, J., \& Bao, M. (2005). The influence of Chinese dress on Western fashion. Journal of Fashion Marketing and Management, 9(2), 166-179. http://dx.doi.org/10.1108/13612020510599321

Fornell, C., \& Larcker, D. F. (1981). Evaluating structural equation models with unobservable variables and measurement error. Journal of Marketing Research, 18, 39-50. Retrieved from http://www.jstor.org/stable/3151312

Gupta, S., \& Miller, N. J. (2010). US consumers' perceptions of garments inspired by Indonesian culture. Journal of Global Fashion Marketing, 1(2), 80-88. http://dx.doi.org/10.1080/20932685.2010.10593060

Ha, J., \& Jang, S. S. (2013). Attributes, consequences, and consumer values: A means-end chain approach across restaurant segments. International Journal of Contemporary Hospitality Management, 25(3), $383-409$. http://dx.doi.org/10.1108/09596111311311035

Hair, J. F., Anderson, R. E., Tatham, R. L., \& Black, W. C. (1998). Multivariate Data Analysis. Upper Saddle River, NJ: Prentice Hall.

Hansen, T. (2008). Consumer values, the theory of planned behviour and online grocery shopping. Internation Journal of Consumer Studies, 32, 128-137. http://dx.doi.org/10.1111/j.1470-6431.2007.00655.x

Homer, P. M., \& Kahle, L. R. (1988). A structural equation test of the value-attitude-behavior hierarchy. Journal of Personality and Social Psychology Association, $\quad 54, \quad 638-46$. http://dx.doi.org/10.1037/0022-3514.54.4.638

Honkanen, P., Verplanken, B., \& Olsen, O. (2006). Ethical values and motives drive organic food choice. Journal of Consumer Behaviour, 5, 420-430. http://dx.doi.org/0.1002/cb.190

Javalgiet, R. G., Khare, V. P., Gross, A. C., \& Scherer, R. F. (2005). An application of the consumer ethnocentrism model to French consumers. International Business Review, 14, 325-344. http://dx.doi.org/10.1016/j.ibusrev.2004.12.006

Jayawardhena, C. (2004). Personal values' influence on e-shopping attitude and behavior. Internet Research, 14, 127-138. http://dx.doi.org/10.1108/10662240410530844

Jöreskog, K. G., \& Sörbom, D. (2006). LISREL 8.80 for Windows [Computer Software]. Scientific Software, Lincolnwood, IL.

Kim, H., \& Drolet, A. (2003). Choice and self-expression: A cultural analysis of variety-seeking. Journal of Personality and Social Psychology, 85, 373-382. http://dx.doi.org/10.1037/0022-3514.85.2.373 
Kim, J. O., Forsythe, S., Gu, Q., \& Moon, S. J. (2002). Cross-cultural consumer values, needs and purchase behavior. Journal of Consumer Marketing, 19, 481-502. http://dx.doi.org/10.1108/07363760210444869

Kim, S., \& Littrell, M. A. (1999). Predicting souvenir purchase intentions. Journal of Travel Research, 38(2), 153-162. http://dx.doi.org/10.1177/004728759903800208

Kim, Y. K., Sullivan, P., \& Forney, J. (2007). Experiential retailing: Concepts and strategies that sell. New York: Fairchild Publications.

Laroche, M., Yang, Z., Kim, C., \& Richard, M. O. (2007). How culture matters in children's purchase influence: A multi-level investigation. Journal of the Academy Marketing Science, 35, 113-126. http://dx.doi.org/10.1007/s11747-007-0016-6

Lavie, T., \& Tractinsky, N. (2004). Assessing dimensions of perceived visual esthetics of web sites. International Journal of Human-Computer Studies, 60, 269-298. http://dx.doi.org/10.1016/j.ijhcs.2003.09.002

Lee, S. E., \& Littrell, M. A. (2006). Marketing cultural products on the internet: targeting cultural creatives. Clothing and Textiles Research Journal, 24(1), 33-45. http://dx.doi.org/10.1177/0887302X0602400103

Leonardelli, G. J., Pickett, C. L., \& Brewer, M. B. (2010). Optimal distinctiveness theory: A framework for social identity, social cognition, and intergroup relations. Advances in Experimental Social Psychology, 43, 63-113. http://dx.doi.org/10.1016/S0065-2601(10)43002-6

Li, H., Daugherty, T., \& Biocca, F. (2002). Impact of 3-D advertising on product knowledge, brand attitude, and purchase intention: the mediating role of presence. Journal of Advertising, 31, 43-57. http://dx.doi.org/10.1080/00913367.2002.10673675

Littrell, M. A., Ogle, J. L. P., \& Kim, S. (1999). Marketing ethnic apparel: single or multiple consumer segments. Journal of Fashion Marketing and Management, 3(1), 31-43. http://dx.doi.org/10.1108/eb022546

Loughran, K. (2009). The idea of Africa in European high fashion: Global dialogues. Fahsion Theroy, 13, 243-272. http://dx.doi.org/10.2752/175174109X414277

Luxury Insider. (2013). Enter the dragon: coach partners Chinese artist Zhang Lan. Luxury Insider. Retrieved from

http://www.luxury-insider.com/luxury-news/2012/01/enter-the-dragon-coach-partners-chinese-artist-zhanglan

Mano, H., \& Oliver, R. L. (1993). Assessing the dimensionality and structure of the consumption experience: Evaluation, feeling and satisfaction. Journal of Consumer Research, 20, 451-66. http://dx.doi.org/10.1086/209361

McCarty, J. A., \& Shrum, L. J. (1994). The recycling of solid wastes: Personal values, value orientations, and attitudes about recycling as antecedents of recycling behavior. Journal of Business Research, 30, 53-62. http://dx.doi.org/10.1016/0148-2963(94)90068-X

Michaelidou, N., \& Hassan, L. M. (2007). The role of health consciousness, food safety concern and ethnical identity on attitudes and intentions towards organic food. International Journal of Consumer Studies, 32, 163-170. http://dx.doi.org/10.1111/j.1470-6431.2007.00619.x

Miller, N. J., Campbell, J. R., Littrell, M. A., \& Travnicek, D. (2005). Instrument development and evaluation for measuring USA apparel product design attributes. Journal of Fashion Marketing and Management, 9(1), 54-70. http://dx.doi.org/10.1108/13612020510586406

Moalosi, R., Popovic, V., \& Hickling-Hudson, A. (2007). Product analysis based on Botswana's postcolonial socio-cultural perspective. International Journal of Design, 1(2), 37-45.

Money, R. B., Gilly, M. C., \& Graham, J. L. (1998). Explorations of national culture and word-of-mouth referral behavior in the purchase of industrial services in the United States and Japan. Journal of Marketing, 62, 76-87. Retrieved from http://www.jstor.org/stable/1252288

Morganosky, M. (1984). Aesthetic and utilitarian qualities of clothing: Use of a multidimensional clothing value model. Home Economics Research Journal, 13, 12-20. http://dx.doi.org/10.1177/1077727X8401300103

Muthen, L. K., \& Muthen, B. O. (2010). Mplus User`s Guide. Authors, Los Angeles, CA.

Nunnally, J. C., \& Bernstein, I. H. (1994). Psychometric Theory. New York, NY: McGraw Hill.

Osborne, H. (1968). Esthetics and Art History. Longman, Harlow. 
Radford, S. K., \& Bloch, P. H. (2011). Linking innovation to design: Consumer responses to visual product newness. Journal of Product Innovation Management, 28(s1), 208-220. http://dx.doi.org/10.1111/j.1540-5885.2011.00871.x

Ralph Lauren. (2013). Men $\quad$ T-shirt. $\quad$ Retrieved from http://www.poloralphlaurenonsale.com/classicfit-dragon-tshirt-freshwater-blue-p-10189.html

Rencher, A. (2002). Methods of Multivariate Analysis. New York, NY: McGraw-Hill.

Reynolds, T. J., \& Gutman, J. (1988). Laddering theory, method, analysis and interpretation. Journal of Advertising Research, 28, 11-31.

Richardson, P. S., Dick, A. S., \& Jain, A. K. (1994). Extrinsic and intrinsic cue effects on perceptions of store brand quality. Journal of Marketing, 58, 28-36. Retrieved from http://www.jstor.org/stable/1251914

Rindova, V. P., \& Petkova, A. P. (2007). When is a new thing a good thing? Technological change, product form design, and perceptions of value for product innovations. Organization Science, 18, 217-232. http://dx.doi.org/10.1287/orsc. 1060.0233

Rodgers, S. (2004). The effects of sponsor relevance on consumer reactions to internet sponsorships. Journal of Advertising, 32, 67-76. http://dx.doi.org/10.1080/00913367.2003.10639141

Salganik, M. J., \& Heckathorn, D. D. (2004). Sampling and estimation in hidden populations using respondent-driven sampling. Sociological Methodology, 34, 193-240. http://dx.doi.org/10.1111/j.0081-1750.2004.00152.x

Satorra, A., \& Bentler, P. (2010). Ensuring positiveness of the scaled difference Chi-square test statistic. Psychometrika, 75, 243-248. http://dx.doi.org/10.1007/s11336-009-9135-y

Scott, L. M. (1994). Images in advertising: the need for a theory of visual rhetoric. Journal of Consumer Research, 21, 252-73. Retrieved from http://www.jstor.org/stable/2489819

Shankarmahesh, M. N. (2006). Consumer ethnocentrism: An integrative review of its antecedents and consequences. International Marketing Review, 23, 146-172. Retrieved from http://www.jstor.org/10.1108/02651330610660065

Sharma, S., Shimp, T. A., \& Shin, J. (1995). Consumer ethnocentrism: A test of antecedents and moderators. Journal of Academy of Marketing Science, 23, 26-37. http://dx.doi.org/10.1007/BF02894609

Sheth, J. N., Newman, B. I., \& Gross, B. L. (1991). Why we buy what we buy: A theory of consumption values. Journal of Business Research, 22, 159-170. http://dx.doi.org/10.1016/0148-2963(91)90050-8

Shoes-Sky. (2013). Mens Nike Air Jordan. Shoes Sky. Retrieved from http://www.shoes-sky.com/mens-nike-air-jordan-retro-11-chinese-red-air-jordan-11-p-2641.html

Steenkamp, J. B. E. M., Batra, R., \& Alden, D. L. (2003). How perceived brand globalness creates brand value. Journal of International Business Studies, 34, 53-65. http://dx.doi.org/10.1057/palgrave.jibs.8400002

Strizhakova, Y., Coulter, R. A., \& Price, L. L. (2008). Branded products as a passport to global citizenship: Perspectives form developed and developing countries. Journal of International Marketing, 16, 57-85. http://dx.doi.org/10.1509/jimk.16.4.57

Sweeney, J. C., \& Soutar, G. N. (2001). Consumer perceived value: The development of a multiple item scale. Journal of Retailing, 77, 203-220. http://dx.doi.org/10.1016/S0022-4359(01)00041-0

Trendwatching. (2013). 10 crucial consumer trends for 2013. Trend Watching. Retrieved from http://www.trendwatching.com/trends/10trends2013/

US Bureau of Census. (2013). Projections of the population by sex, race, and Hispanic origin for the United States: 2010 to 2050 high net international migration series. US Bureau of Census. Retrieved from www.census.gov/population/projections/files/summary/NP2009-T4-H.xls

Verplanken, B., \& Holland, R. (2002). Motivated decision making: effects of activation and self-centrality of values on choices and behaviour. Journal of Personality and Social Psychology, 82(3), 434-447. http://dx.doi.org/10.1037/0022-3514.82.3.434

Veryzer Jr., R. W. (1993). Esthetic response and the influence of design principles on product preferences. Advances in Consumer Research, 20, 224-228.

Vinson, D. E., Munson, J. M., \& Nakanishi, M. (1977). An investigation of the Rokeachvalue survey for consumer 
research applications. Advances in consumer research, 4(1), 247-252.

Vinson, D. E., Scott, J. E., \& Lamont, L. M. (1977). The role of personal values in marketing and consumer behavior. Journal of Marketing, 42, 44-50. Retrieved from http://www.jstor.org/stable/1250633

William, P., \& Soutar, G. N. (2009). Value satisfaction and behavioral intentions in an adventure tourism context. Annals of Tourism Research, 36, 413-438. http://dx.doi.org/10.1016/j.annals.2009.02.002

Xu, J., Shim, S., Lotz, S., \& Almeida, D. (2004). Ethnic identity, socialization factors, and culture-specific consumption behavior. Psychology \& Marketing, 21, 93-112. http://dx.doi.org/10.1002/mar.10117

Zhang, Y., \& Khare, A. (2009). The impact of accessible identities on the evaluation of global versus local products. Journal of Consumer Research, 36, 524-537. Retrieved from http://www.jstor.org/stable/10.1086/598794

\section{Copyrights}

Copyright for this article is retained by the author(s), with first publication rights granted to the journal.

This is an open-access article distributed under the terms and conditions of the Creative Commons Attribution license (http://creativecommons.org/licenses/by/3.0/). 